\title{
Flawed Ideologies, Propaganda and the Social Situatedness of Knowledge
}

\author{
Maria Cristina Amoretti \\ University of Genoa
}

\begin{abstract}
In this paper I focus on the connection between some of Stanley's claims about propaganda and flawed ideologies, and the idea of the social situatedness or perspective-relativity of knowledge. More precisely, I will try to show how Stanley's reflections on the nature of propaganda and its relationship with flawed ideologies push us towards the empiricists' characterisation of the social situatedness of knowledge. Not only do these reflections reveal some important weaknesses of standpoint theories (that is, the claim of epistemic asymmetry between advantaged and negatively advantaged groups, and the necessity of actively achieving a standpoint), but they also support the request for the pluralism, rational critique, cooperation, fair discussion and epistemic integration fostered by social empiricism. This means that the broad idea of the social situatedness of knowledge should be defended and further developed along the lines sketched by social empiricism.
\end{abstract}

\section{Keywords}

Flawed ideologies, propaganda, social empiricism, social situatedness of knowledge, standpoint theories.

\section{Introduction}

Jason Stanley's last book, How Propaganda Works (2015), has many interesting and fertile epistemological implications that will certainly be important to consider. Unfortunately, as it would be impossible to address all of them in only one paper, I will focus on one very specific issue: the connection between some of Stanley's claims about propaganda and flawed ideologies, and the idea of the social situatedness or perspective-relativity of knowledge. 
Roughly speaking, saying that our knowledge is socially situated means that one's social situation - which consists of one's ascribed social identities (gender, race, sexual orientation, ethnicity, social class, religion, etc.) and social roles (family, occupation, political party membership, etc.) — enables, favours and yet limits one's knowledge abilities and possibilities. To put it another way, it means that knowledge of the natural and/or social world somehow reflects the social situation, the ascribed social identities and roles, of particular knowers. Partly by virtue of their social situation, individuals in fact acquire different values and biases (connected to their social powers, duties, role-given goals, interests, subjective identities, etc.), which together affect their knowledge (Anderson 2015). Of course, there are many ways to further develop the broad idea of the social situatedness of knowledge, but I shall consider just two, which have mainly been developed by feminist epistemologists in relation to scientific knowledge: standpoint theories and social empiricism (for a thorough comparison of these two views, see Intemann 2010).

On the one hand, standpoint theories (typically feminist, standpoint epistemologies_-Hartsock 1983; Harding 1986, 1991, 1993, 1998, 2004; Collins 1990) articulate the idea that knowledge is situated, stressing the importance of perspectival differences stemming from social location: they claim that there is a pivotal epistemic difference between the social position of negatively advantaged groups and that of advantaged groups, as the former are far less partial and distorted than the latter. The epistemic privilege of the negatively advantaged groups, however, is not automatically associated with their social location, as this must be discovered and collectively achieved through a process of political struggle, collective action and consciousness-raising. Even if standpoint theories come in different strengths (some making bold claims about the epistemic benefits of social marginalisation and subordination, others making more cautious statements), there is the idea that negatively advantaged social situations are, at least in principle, epistemically privileged or more epistemically reliable than advantaged ones.

On the other hand, social empiricism (typically that developed in a feminist framework-Longino 1990, 2001; Nelson 1990, 1993) endorses the idea that knowledge is situated and somehow partial, but maintains that in order to obtain a (more) objective perspective 
and further our knowledge about the natural and/or social world there is no need to look for either an impartial position or an epistemically privileged one, as what really counts is to rationally compare and debate all various perspectives so as to minimise the negative influence of individual values and biases. What is needed is thus a system in which critical, pluralistic, cooperative and fair discussion between a variety of differently socially situated individuals is actually feasible. Of course, the main problem is exactly that of eliciting such a system.

In what follows, I will try to show how Stanley's reflections on the nature of propaganda and its relationship with flawed ideologies push us towards the empiricists' characterisation of the social situatedness of knowledge. Not only do these reflections cast doubt on the standpoint theorists' claim that negatively advantaged social positions come, at least in principle, with epistemic privilege, but they also reinforce the social empiricists' claim that pluralistic discussions are of pivotal epistemic importance.

\section{Social situation and flawed ideologies}

According to Stanley (2015), ideologies are beliefs that are particularly resistant to available counter-evidence, and that contribute to their own unrevisability. This is especially due to the 'structural features of the society in which the agent is located' (2015: 179): ideological beliefs are connected to one's various identities which one shares with others, and thus they would be hard to abandon insofar as this would imply abandoning those very identities (2015: 188). This definition of ideologies is clearly over-inclusive, as even genuine and legitimate pieces of knowledge or unimportant falsities can count as ideologies in this broad sense.

Stanley claims that ideologies become truly epistemologically problematic, and thus flawed, once they prevent us from gaining knowledge about important features of the natural and/or social world (2015: 198). Flawed ideologies, unlike mere ideologies, involve false ideological beliefs that are resistant to rational revision and are able to obstruct and prevent the acquisition of knowledge about aspects of natural and/or social reality. Beliefs can be resistant to rational revision for all sorts of reasons, but Stanley focuses 
on ideologies that are flawed 'because of structural features of society that inhibit the rational revision of pre-existing false belief, to preserve a desirable situation for a privileged group' (2015: 199). Flawed ideologies obstruct our knowledge because not only do they favour different kinds of epistemic injustice (i.e. testimonial and hermeneutical injustice-Fricker 2007) towards negatively advantaged groups, but they also alter our perceptual mechanisms and the route from perception to perceptual beliefs, and thus detrimentally affect the evidence that would otherwise be needed to gain justification and knowledge. In this sense, Stanley's definition of flawed ideology seems to be somewhat paradoxical: how can there be any relevant counter-evidence if what eventually counts as evidence is shaped and determined by the flawed ideology itself?

Stanley argues that flawed ideologies tend to arise within societies that are characterised by conditions of material (unjust) inequalities, hierarchical structures and subordination, where those conditions contrast with certain beliefs and values about oneself and one's group. The story is quite simple. Within democratic societies that are also characterised by material inequalities, the members of advantaged groups happen to be in their privileged social position without any real merit; however, this fact contrasts with their own beliefs and values, which in a democracy include fairness and equality. In order to hide this contradiction, the members of advantaged groups convince themselves that their privileged social position has been obtained on merit and thus is deserved. In the long run, this tends to enable a lack of empathy towards members of negatively advantaged groups, who come to be seen as inferior and rightly deserving of their subordinate and underprivileged position. In this way, in order to mask their undeserved privileges the members of advantaged groups start developing self-legitimising myths about their own superiority. These self-legitimising myths give rise to flawed ideological beliefs, which in turn strengthen the myths. To sum up, if in a democracy the members of advantaged groups have their privilege without deserving it and thus cultivate self-legitimising myths in order to hide the contradiction between their status and the democratic ideals of fairness and equality, flawed ideologies arise. Advantaged groups then keep their flawed ideology, as it directly contributes to its own unrevisability. For example, flawed ideologies 
favour testimonial injustice: relevant testimonies from members of negatively advantaged groups are not taken to be credible and thus cannot be exploited to unmask flawed ideologies and self-legitimising myths. Moreover, flawed ideologies alter the perceptions, or at least the perceptual beliefs, of the members of advantaged groups to prevent them from accessing relevant counter-evidence.

Given all that, one might reasonably hope that the members of negatively advantaged groups would be immune to flawed ideologies and thus in a better position to detect and unmask them. If so, negatively advantaged groups would be epistemically privileged or more epistemically reliable as their social position, at least in principle (for instance, through a process of political struggle, collective action and consciousness-raising), would allow them to know features of the natural and/or social world that are invisible to advantaged groups. However, this seems not to be the case.

In fact, according to Stanley the members of negatively advantaged groups also readily come to accept and share the same flawed ideology possessed by advantaged groups (2015: 234-7). The primary reason is that the members of advantaged groups not only sincerely endorse flawed ideologies, typically they also control 'the dominant public narrative' through education and information systems (schools, media, etc.). As a consequence, even negatively advantaged groups spontaneously absorb the flawed ideology of the advantaged groups from both the testimony of authority figures, such as teachers, professors, journalists, anchormen, etc., and the lack of reliable sources that contradict them. Yet one might hope that members of negatively advantaged groups would still be in a better position to realise that their own ideology is actually flawed, because they are directly exposed to explicit counter-evidence. Again, this seems not to be the case (2015: 251-60). As Stanley points out, negatively advantaged groups tend in fact to maintain the flawed ideology of the advantaged groups, even in the face of explicit counter-evidence, for different important reasons: because they suffer from testimonial injustice, they typically lose their epistemic confidence and thus the possibility of knowing about different important aspects of natural and/or social reality; because they also suffer from hermeneutical injustice, they are systematically deprived of the relevant conceptual resources needed to recognise and appreciate important aspects of 
the social world, such as their own subordinate condition; because they face high-stakes decisions, higher stakes than those faced by advantaged groups, they must gather more additional evidence to gain knowledge about something that is the basis for their decisions (interest-relativity of knowledge); and finally, because they have perceptions, or at least perceptual beliefs, altered by the flawed ideology of advantaged groups - ideology that they endorse - significant counter-evidence is either prevented or masked.

This is certainly a very plausible account, which clearly explains why certain flawed ideologies are present in Western democratic societies and shared by both advantaged and negatively advantaged groups. Of course, it is more an a posteriori reconstruction than a general argument, as it does not show that conditions of material (unjust) inequalities plus an endorsement of democratic values are by themselves sufficient to produce flawed ideologies affecting both advantaged and negatively advantaged groups. There is actually no obvious conceptual link between conditions of material unjust inequalities, self-legitimising myths and flawed ideologies. Similarly, there is no general argument showing that conditions of material equality plus an endorsement of democratic values would by themselves be sufficient to prevent the appearance of flawed ideologies. Moreover, it is worth noting that the above account becomes less and less plausible should the material inequalities be just and realised because of the inherent merit of the advantaged groups. Stanley considers such a possibility, and explains that in this case flawed ideologies would instead arise among the members of the disadvantaged groups, who would not accept the fact that their subordinate condition is actually deserved. This, again, is very plausible, but the flawed ideology would be restricted to negatively advantaged groups and not shared by the members of advantaged groups, who would likely continue to believe that they deserved their privileged position. To sum up, it has not been demonstrated that conditions of material inequalities, just or unjust, plus an endorsement of democratic values, systematically lead to pervasive flawed ideologies. Nor has it been demonstrated that conditions of unjust material inequalities plus an endorsement of democratic values are by themselves sufficient to give rise to flawed ideologies, or conversely that conditions of material equality plus an endorsement of democratic values are by themselves sufficient to 
prevent flawed ideologies. That being said, the above goals are not Stanley's; he aims instead to show that conditions of material unjust inequalities, which undoubtedly characterise Western democratic societies, plus an endorsement of democratic values, have contingently given rise to flawed ideologies that are accepted and maintained by both advantaged and negatively advantaged groups. This conclusion will suffice for the scope of this paper.

If one accepts Stanley's arguments aiming to show that in Western democratic societies flawed ideologies are accepted and maintained by both advantaged and negatively advantaged groups, it seems to me that one should also deny the idea that negatively advantaged groups are epistemically privileged or more epistemically reliable because of their subordinate and marginalised social situation. I endorse the idea that there is no social and/or cultural fact concerning the negatively advantaged groups that makes them epistemically privileged or more epistemically reliable than the advantaged ones (Amoretti and Vassallo 2010, 2012, 2013). But this is contrary to what standpoint epistemologists would instead be eager to claim - arguing that, at least in principle (after a process of political struggle, collective action and consciousness-raising), negatively advantaged groups are to be judged epistemically privileged or more epistemically reliable. Given Stanley's scenario, knowledge would be obstructed and prevented by the very same flawed ideologies, those of the advantaged groups, that arise and maintain themselves through very different yet equally effective ways. In particular, negatively advantaged groups would not only spontaneously absorb and share the flawed ideology of the advantaged groups, but they also would tend to keep it, even in the face of explicit counter-evidence.

One may be sceptical about this claim, and believe that those who belong to negatively advantaged groups and accept flawed ideologies are nevertheless in a better social position to engage in ideology critique than those who accept flawed ideologies and belong to advantaged groups. The epistemic privilege that standpoint theorists attribute to negatively advantaged groups may just consist in their being less resistant to revising their flawed ideologies than those who are socially advantaged. However, it seems to me that, even granting that advantaged and negatively advantaged groups are differently exposed to explicit counter-evidence, Stanley offers good reasons to 
suppose that both groups are equally, or at least similarly, resistant to revising their flawed ideologies. Of course, the mechanisms that prevent them from engaging in ideology critique are quite different (as I briefly summarised a few paragraphs above), but if they are equally, or at least similarly, effective, we cannot acknowledge that negatively advantaged groups who accept flawed ideologies are still in a better position to engage in ideology critique. Amia Srinivasan recently made a similar, or even stronger, claim noting that 'Stanley sees the oppressed as epistemological victims, and the elite as epistemological miscreants who might still be reformed' (2016: 378). Srinivasan regards this point as a weakness in Stanley's position, while I endorse and use it against standpoint theories. However, we both see a tension between what Stanley says about members of negatively advantaged groups internalising and maintaining flawed ideologies about themselves, and the standpoint theorists' idea that negatively advantaged groups are in a better epistemic position to engage in the critique of flawed ideologies.

That being said, the idea of the social situatedness of knowledge is independent of those of epistemic asymmetry, privilege and better reliability. Accepting the social situatedness of knowledge can simply mean accepting the idea that each knower has a particular perspective on the natural and/or social world that is determined by his/her social situation and characterised by, among other things, certain perspectival biases and values. These biases and values typically differ between advantaged and negatively advantaged groups, but they can also be transversal to them. Flawed ideological beliefs are obviously part of one's social situation because they are connected to one's various identities, and yet they do not exhaust it. Thus, particular social situations in specific contexts and moments can make it easier to recognise the inherent flaws of a certain ideology. That a particular social group happens to be more or less resistant to revising its flawed ideologies seems to depend on many different and contingent factors that are not exclusively linked to social advantage/disadvantage. To put it another way, some perspectival biases and values, in the appropriate circumstances, can make it easier to undermine flawed ideological beliefs as they might increase someone's interest in raising and addressing new questions, reassessing alleged neutral perceptions, actually considering (or even shaping 
new) counter-evidence and then developing new tools that are able to unmask specific flawed ideologies.

The relevant point here is that flawed ideology cannot be directly undermined by counter-evidence, but rather it can be dismissed by another ideology. This means that it is not possible to establish once and for all which social situation might be better suited to undermine certain flawed ideologies, as there is no obvious feature (such as disadvantage, subordination or marginalisation) that makes some social groups epistemically privileged or more epistemically reliable than others. If this is true, then as some social epistemologists and feminist epistemologists committed to social empiricism have convincingly argued with regard to scientific endeavours (Kitcher 1993; Longino 1990, 2001), in order to obtain more objective beliefs and further our knowledge it is important to integrate different points of view within the same social group, improving interactions across different social groups, and-more importantly_promoting pluralism and, of course, recognition of the epistemic authority of every single social perspective. It is worth noting that endorsing the social empiricists' view on the social situatedness of knowledge does not lead to an embrace of epistemological relativism in any of its forms, as a more objective perspective can be obtained from differently biased ones. Social empiricism simply asks us to recognise that social situations are not neutral or objective, but inevitably include values, biases and flawed ideological beliefs, and that objectivity can thus be reached through the confrontation of different social situations, depending on the ability to respond to criticism from all points of view.

To sum up, Stanley has cleverly noted that the same flawed ideologies can be accepted and maintained by both advantaged and negatively advantaged groups, neither of which is epistemically privileged or epistemically more reliable than the other, not even in principle, just because of their advantaged or negatively advantaged position. This means that standpoint epistemologies would be wrong to defend the epistemic privilege of the negatively advantaged groups. However, as each specific social situation is also characterised by other distinctive perspectival biases and values, which may be transversal to advantaged and negatively advantaged groups, this would explain why some particular social situations may be contingently better suited than others to uncovering and undermining specific 
flawed ideologies. As flawed ideologies cannot be directly revealed and reversed by counter-evidence we should promote ideological pluralism, as social empiricism recommends and as Stanley recognises when he says that there are 'two structural sources of flawed ideological belief in a society. The first is substantive failures of equality of different sorts. The second is ideological uniformity' (2015: 231).

\section{Social situation and propaganda}

Stanley's characterisation of propaganda is novel and provocative as it challenges some plausible and widespread assumptions, such as: (i) propagandistic claims are false, or at least communicate something false (the falsity condition), and (ii) propagandistic claims must be delivered insincerely (the insincerity condition). More precisely, he believes that 'a true claim, uttered with sincerity, can be propaganda' (2015: 42).

Stanley interestingly distinguishes two kinds of propaganda: supporting and undermining propaganda. The former is 'a contribution to public discourse that is presented as an embodiment of certain ideals, yet is of a kind that tends to increase the realization of those very ideals by either emotional or other nonrational means' (2015: 53), while the latter is 'a contribution to public discourse that is presented as an embodiment of certain ideals, yet is of a kind that tends to erode those very ideals. [...] It's an argument that appeals to an ideal to draw support, in the service of a goal that tends to erode the realization of that ideal' (2015: 53). With the above definition of undermining propaganda, it becomes clear why flawed ideology is needed: flawed ideological beliefs mask the contradiction between ideal and goal, and thus make undermining propaganda possible. Let us analyse some feasible consequences of propaganda for the idea of the social situatedness of knowledge, starting with undermining propaganda.

Undermining propaganda depends on exploiting flawed ideological beliefs; if Stanley is right that flawed ideologies affect both advantaged and negatively advantaged groups, then, at least prima facie, undermining propaganda would be equally effective in all social situations. However, one's social situation, which consists of one's ascribed social identities and social roles, is not exhausted by flawed ideological beliefs because, as I have argued in the previous section, it is also characterised by a complex set of perspectival biases and values 
(concerning gender, race, sexual orientation, ethnicity, social class, religion, family, occupation, political orientation, etc.), that typically differ between advantaged and negatively advantaged groups but can also be transversal to them. Undermining propaganda exploits flawed ideologies that group members within a society already hold, but flawed ideological beliefs may be reinforced, weakened or even dismantled by the presence of other perspectival biases and values characterising a particular social situation. To clarify, undermining propaganda may not be equally effective in all social situations; however, its being more or less effective seems to depend on many different and contingent factors that are not exclusively linked to social advantage/disadvantage. If this is true, then two points may be noted. First, contrary to what standpoint epistemologies would probably claim, the effectiveness of undermining propaganda is not directly linked to the social advantage/disadvantage of a particular group's position, as many other factors are actually in play. Second, in line with social empiricism, the possibility of recognising and blocking undermining propaganda seems to increase with the number of social situations that are involved in a rational debate, as the chance to include social situations contingently better suited to detecting and unmasking flawed ideologies would be higher. Once again, promoting pluralism and recognising the epistemic authority of every single social perspective becomes pivotal, as social empiricism maintains.

Unfortunately, undermining propaganda also has the power to strengthen the flawed ideological beliefs that the members of both advantaged and negatively advantaged groups within a society already hold. If this is the case, then it prevents or at least makes more complicated the detection and rejection of flawed ideological beliefs. It is worth noting that, in this case too, the success of undermining propaganda is not directly linked to the social advantage/disadvantage of a particular group, but rather to the presence of a rich set of other perspectival biases and values. Moreover, the presence of undermining propaganda, together with the various reasons Stanley identifies to explain the presence and maintenance of flawed ideological beliefs among the members of negatively advantaged groups, also seem to compromise the possibility of them collectively achieving their standpoint through a process of political struggle, collective action and consciousness-raising - and this would clearly weaken 
another important tenet of standpoint theories (in fact, even admitting the epistemic privilege of negatively advantaged standpoints, it would be extremely difficult to achieve).

If the success of undermining propaganda does not merely depend on the presence of flawed ideologies but also on what other specific perspectival biases and values are at stake in each particular social situation, some social situations will be better suited than others to detecting and unmasking flawed ideologies due to these additional perspectival biases and values. Hence, it is important to understand what biases and values are 'good' and what biases and values are 'bad' (Antony 1993). Intuitively, as Stanley recognises in talking about epistemologically non-problematic ideologies, it would be easy to recognise that some biases and values, the 'good' ones, are particularly suited to getting rid of flawed ideologies, recognising undermining propaganda and then blocking it; while other biases and values, the 'bad' ones, reinforce flawed ideologies and thus contribute to the success of undermining propaganda.

The problem here is that of systematically promoting 'good' biases and values over 'bad' ones. Within a society or social group in which the latter prevail, it seems that it would be difficult or even impossible to rationally defend and promote the former. Nevertheless, I think that in similar situations supporting propaganda, as depicted by Stanley, can be very helpful, as it can contribute to fostering good biases and values by either emotional or other non-rational means where their defense through rational means is clearly precluded. As Stanley notes,'a contribution to a debate can improve the subsequent reasonableness of the debate, even though the contribution itself is not a rational contribution' (2015: 112). Thus, supporting propaganda can ultimately be helpful in eliciting the system needed by social empiricism, a system in which critical, pluralistic, cooperative and fair discussion between a variety of differently socially situated individuals is actually feasible.

To conclude, I believe that Stanley's reflections on propaganda and flawed ideologies reveal some important weaknesses of standpoint theories (that is, the claim of epistemic asymmetry between advantaged and negatively advantaged groups, and the necessity of actively achieving a standpoint), while at the same time supporting the request for the pluralism, rational critique, cooperation, fair 
discussion and epistemic integration fostered by social empiricism. To put it more simply, I take Stanley's book to show that the broad idea of the social situatedness of knowledge should be defended and further developed along the lines sketched by social empiricism. ${ }^{1}$

Maria Cristina Amoretti DAFIST, Philosophy Section University of Genova

Via Balbi 4, 16126 Genova, Italy cristina.amoretti@unige.it

\section{References}

Amoretti, M.C.; and Vassallo, N. 2010. Do feminist standpoint epistemologies of the sciences answer the charge of essentialism? In Architectures of Theoretical and Practical Knowledge: Epistemology, Agency, and Sciences, ed. by M. De Caro and R. Egidi. Roma: Carocci.

Amoretti, M.C.; and Vassallo, N. 2012. On the independence of the social and situated dimension of scientific knowledge from the notion of standpoint. In Gendered Ways of Knowing in Science: Scope and Limitations, ed. by S. Knauss, T. Wobbe and G. Covi. Trento: FBK Press.

Amoretti, M.C.; and Vassallo, N. 2013. A way of saving normative epistemology? Scientific knowledge without standpoint theories. In EPSA11 Perspectives and Foundational Problems in Philosophy of Science, ed. by V. Karakostas and D. Dieks. Dordrecht: Springer.

Anderson, E. 2015. Feminist epistemology and philosophy of science. In The Stanford Encyclopedia of Philosophy, ed. by E.N. Zalta, http://plato.stanford. edu/entries/feminism-epistemology/ (last access: August 25, 2016).

Antony, L. 1993. Quine as feminist: the radical import of naturalized epistemology. In A Mind of One's Own: Feminist Essays on Reason and Objectivity, ed. by L. Antony and C. Witt. Boulder: Westview Press.

Collins, P.H. 1990. Black Feminist Thought. Knowledge, Consciousness, and the Politics of Empowerment. London: Routledge.

Fricker, M. 2007. Epistemic Injustice: Power and the Ethics of Knowing. Oxford: Oxford University Press.

Harding, S. 1986. The Science Question in Feminism. Ithaca: Cornell University Press. Harding, S. 1991. Whose Science? Whose Knowledge? Thinking from Women's Lives. Ithaca: Cornell University Press.

Harding, S. 1993. Rethinking standpoint epistemology: what is strong objectivity?

'I would like to thank Elisabetta Lalumera, Nicla Vassallo, Dan Zeman, and two anonymous reviewers from Disputatio for their very insightful comments and constructive criticisms. 
In Feminist Epistemologies, ed. by L. Alcoff and E. Potter. London: Routledge. Harding, S. 1998. Is Science Multicultural? Postcolonialisms, Feminisms, and

Epistemologies: Race, Gender, and Science. Bloomington: Indiana University Press. Harding, S. (ed.) 2004. The Feminist Standpoint Theory Reader. London: Routledge.

Hartsock, N. 1983. The feminist standpoint: developing the ground for a specifically feminist historical materialism. In Discovering Reality, ed. by S. Harding and M.B. Hintikka. Dordrecht: Kluwer.

Intemann, K. 2010. 25 years of feminist empiricism and standpoint theory: where are we now? Hypatia 25(4): 778-96.

Kitcher, P. 1993. The Advancement of Science: Science without Legend, Objectivity without Illusions. Oxford: Oxford University Press.

Longino, H.E. 1990. Science as Social Knowledge: Values and Objectivity in Scientific Inquiry. Princeton: Princeton University Press.

Longino, H.E. 2001. The Fate of Knowledge. Princeton: Princeton University Press. Nelson, L.H. 1990. Who Knows: From Quine to a Feminist Empiricism. Philadelphia: Temple University Press.

Nelson, L.H. 1993. Epistemological communities. In Feminist Epistemologies, ed. by L. Alcoff and E. Potter. London: Routledge.

Srinivasan, A. 2016. Philosophy and ideology. Theoria 31(3): 371-80.

Stanley, J. 2015. How Propaganda Works. Princeton: Princeton University Press. 